\title{
SELEÇÃO E INGRESSO DE ESTUDANTES REFUGIADOS NO ENSINO SUPERIOR BRASILEIRO: A INSERÇÃO LINGUÍSTICA COMO CONDIÇÃO DE HOSPITALIDADE
}

\section{BRAZILIAN HIGHER EDUCATION ADMISSIONS PROCESS FOR REFUGEE STUDENTS: THE LINGUISTIC INSERTION AS A CONDITION OF HOSPITALITY}

Marluza da Rosa*

\section{RESUMO}

Este estudo problematiza as relações de saber-poder em que se inscrevem as políticas de hospitalidade direcionadas ao acesso de estudantes refugiados às universidades públicas brasileiras nos últimos anos. A análise dedica-se à abordagem da materialidade linguística de documentos institucionais que regulamentam esse ingresso, buscando compreender, pelo diálogo entre os estudos da psicanálise, da desconstrução e do discurso, os efeitos de sentido decorrentes do discurso institucional. Os recortes discutidos apontam para o caráter normativo e prescritivo desse discurso e permitem a reflexão sobre o papel exercido pela língua portuguesa como principal condicionante que, ao mesmo tempo, possibilita e impossibilita o acesso de pessoas em situação de refúgio à universidade brasileira.

Palavras-chave: refugiados; universidade; hospitalidade.

\section{ABSTRACT}

This study discusses knowledge/power relations present in policies on hospitality tailored to enable access to Brazilian universities for refugee students. The analysis focus on the linguistic materiality of institutional documents to understand the effects of meaning from institutional discourse. The discussion, based on psychoanalysis, deconstruction and discourse theories, emphasize the normative and prescriptive character of this discourse and the role played by the Portuguese language as the main condition that, at the same time, makes it possible and impossible for refugees to enroll in Brazilian public higher education. Keywords: refugees; university; hospitality.

\section{CONSIDERAÇÕES INICIAIS}

A partir de agora, sabemos que somos estrangeiros de nós mesmos e a partir desse único apoio é que podemos tentar viver com os outros (KRISTEVA, 1994).

\footnotetext{
* Universidade Federal de Santa Maria, campus Frederico Westphalen, UFSM/FW, RS, Brasil. marluza. rosa@gmail.com
} 
O estrangeiro é aquele que, "ao colocar a primeira questão, me questiona". Assim Derrida (2003, p. 5) o define em Da Hospitalidade, entrevista concedida a Anne Dufourmantelle, no início deste século. Contudo, apesar dessa definição (ou talvez exatamente devido a ela), o estrangeiro enquanto tal não é assim tão facilmente apreensível ou compreensível. Do estrangeiro, aquele que nos é estranho, desconhecido, quase nada sabemos. Da estrangeiridade, característica não apenas do que é de fora, mas de nossa própria constituição, nada queremos saber. O estrangeiro é o outro, os outros, assim como o inferno são os outros e deles nada nos diria respeito. Nunca vemos a nós mesmos como estrangeiros, a menos que haja um deslocamento, uma ruptura, um abalo na solidez do lugar onde estamos. Porém, normalmente, o que é próprio dos lugares é serem estáveis, uma vez que a estabilidade faz parte da concepção mesma do que seja um lugar; mas há lugares mais estanques do que outros, seja porque se os veem como locais de/da verdade, seja porque se teme, por alguma razão, balançá-los. Assim, é pertinente que nos perguntemos sobre o lugar que a Universidade assume contemporaneamente: de que ordem seria? Quão estanque se nos apresenta?

Nas pesquisas que temos desenvolvido, a Universidade é esse lugar que nos sustenta, mas que também buscamos desestabilizar, em um gesto, de alguma forma, parricida. Principal fonte de culpa e sofrimento para os homens, segundo Freud (1980), o parricídio é, também, um mito fundador da cultura. Desse modo, o questionamento da Universidade em sua estabilidade secular e a morte do pai (o parricídio) podem ser lidos como dois movimentos, ou duas faces de um mesmo movimento, que nos deixam deslocados, mas que são determinantes para fundarmos novas formas de pensar, de viver e de agir com o outro, embora não raro nos provoquem certo malestar. É por essa via que nos aproximamos da condição de estrangeiros, migrantes, pois "o sofrimento do migrante está vinculado à desestabilização de prévias certezas, ameaçando a identidade em seu próprio fundamento. $\mathrm{O}$ migrante em sua estrangeiridade é inclassificável, sem lugar, nem cidadão nem estrangeiro, se situa na fronteira entre o ser e o não ser" (SILVA; CREMASCO, 2015, n./p.); fronteira esta que nossos estados, nossas instituições teimam em manter.

No que concerne à Universidade, mais precisamente, ao mesmo tempo em que se propõe como um universo, ainda tem funcionado, na prática, como lugar fechado, o que nos remete, por outro olhar, aos termos de Glissant (2005, p. 3536), quando afirma que "o lugar de onde emitimos a fala, de onde emitimos o texto, de onde emitimos a voz, de onde emitimos o grito, esse lugar é imenso. Mas podemos fechar esse lugar, e nos enclausurarmos dentro dele". Assim podemos acompanhar, em grande medida, o funcionamento de nossas universidades, que 
se querem internacionalizadas, e nossa tentativa constante de a elas pertencer. Contudo, esse pertencimento só pode se dar na medida em que pensemos dentro e contra a instituição, ou seja, desestabilizando, por meio do exercício constante do pensamento (auto)crítico, seus domínios estanques. Por essa razão, neste trabalho, buscamos problematizar a Universidade e seu discurso institucional que, apesar das reconfigurações, reestruturações, reformas, permanece o lugar do mesmo, da estabilização dos sentidos; problematizamo-la por meio da relação sujeito-língua, que aponta, necessariamente, para o diferente, o outro, o estranho.

A motivação deste estudo se deve à recente abertura de editais para o ingresso de refugiados em nossas universidades, na conjuntura decorrente não só das políticas de ação afirmativa, implantadas desde o início dos anos 2000, mas também das políticas migratórias, pautadas na Lei n. 9.474/1997, que trata do Estatuto dos Refugiados. A referida lei define mecanismos para implementação desse Estatuto, proposto desde 1951, e prevê, dentre outros aspectos, que "o reconhecimento de certificados e diplomas, os requisitos para a obtenção da condição de residente e o ingresso em instituições acadêmicas de todos os níveis deverão ser facilitados, levandose em consideração a situação desfavorável vivenciada pelos refugiados" ${ }^{\prime \prime}$. Tomamos como propósito, então, a análise de documentos que regulamentam o ingresso de pessoas em situação de refúgio em universidades públicas brasileiras.

Em um primeiro momento, refletimos sobre a condição do estrangeiro, se é que podemos falar de uma condição para todas as formas de estrangeiridade, inserindo aí o estatuto do refugiado no Brasil. Em um segundo momento, tratamos da problemática da hospitalidade, convertida em um neologismo, "hostipitalidade", por Derrida (2000). Por fim, em um terceiro momento, abordamos as condições de produção referentes ao processo de abertura das Instituições de Ensino Superior (IES) públicas brasileiras, analisando mais pontualmente os documentos de algumas delas, que regulam o ingresso "facilitado" de pessoas em situação de refúgio em seus domínios.

\section{BUSCAR REFÚGIO, UMA CONDIÇÃO PARRICIDA}

Há mais de vinte anos, desde julho de 1997, temos em nosso sistema judiciário a Lei $\mathrm{n}^{\circ}$ 9.474, mais conhecida como Estatuto do Refugiado, que estabelece as condições de permanência de pessoas em situação de refúgio no Brasil. Com essa lei sancionada, à época, e com o processo de consolidação do CONARE (Comitê

1. O texto da lei pode ser acessado em: http://www.planalto.gov.br/ccivil 03/leis/L9474.htm. Grifo nosso. 
Nacional dos Refugiados), o país assumia uma postura pioneira e protagonista, a qual se mantém até nossos dias. É nesse documento e por meio de seu funcionamento que se estabelece um lugar para as pessoas em situação de refúgio: o refugiado está em uma posição diferente, garantida por lei, da do imigrante, do exilado, do estrangeiro. Segundo a lei de 1997,

Art. $1^{\circ}$ Será reconhecido como refugiado todo indivíduo que:

I - devido a fundados temores de perseguição por motivos de raça, religião, nacionalidade, grupo social ou opiniões políticas encontre-se fora de seu país de nacionalidade e não possa ou não queira acolher-se à proteção de tal país;

II - não tendo nacionalidade e estando fora do país onde antes teve sua residência habitual, não possa ou não queira regressar a ele, em função das circunstâncias descritas no inciso anterior;

III - devido a grave e generalizada violação de direitos humanos, é obrigado a deixar seu país de nacionalidade para buscar refúgio em outro país (BRASIL, n./p., 1997).

Três feridas, portanto, marcam a condição do refugiado: a perda da origem, a necessidade do deslocamento e a impossibilidade do retorno. Se a problemática do estrangeiro já se configura como um paradigma, um vazio que, ao mesmo tempo, abriga o estranho e o exótico, a do refugiado dela se aproxima, mas também se distingue. $\mathrm{O}$ refugiado, pelo seu estatuto, supostamente se beneficia de garantias morais, éticas, jurídicas. Ser refugiado, conforme a lei, é uma "condição jurídica" que lhe confere direitos inalienáveis e que não se estende a qualquer estrangeiro ou errante. Mas, o que implica conferir um lugar a essa categoria de estrangeiros em nossa lei, em nosso conjunto de normas jurídicas, senão o gesto civilizatório de tornar semelhante o dessemelhante, de generalizar e abstrair sua singularidade, de degluti-lo? Não se deveria, pelo contrário, compreender que "aqueles que migram, alguns dos quais movidos pela energia do desespero, interrogam a univocidade do relato que os fundamenta, a fim de escrever, no exílio, um novo relato de sua origem" (NATAHI, 2007, p. 164)? Se concebemos o brasileiro como povo cordial e hospitaleiro, não podemos nos esquecer de que essa cordialidade parece se dar sempre e apenas para com o semelhante.

Como todo aquele que se desloca, quem busca refúgio vivencia não apenas o que Régine Robin (2003) chama de "o luto da origem", mas também a experiência do parricídio. Diferentemente do imigrante, não é apenas em busca de uma pátria-mãe permissiva e da promessa de um lugar melhor que o refugiado parte. É sobretudo porque ele é e precisa continuar sendo parricida - patricida -, matar em si e fazer o luto (de forma metafórica, evidentemente) desse pai tirano, totalitário, onipresente, a fim de que consiga fundar novamente uma cultura para si. Segundo Natahi (2007, 
p. 165), "aquele que se expatria recolhe a ordem de um mal-estar em que se delineia o entrelaçamento de corpos, língua e morte".

Se a imagem do país natal funciona como metáfora paterna e se esse mesmo país impede seus filhos de assumirem um lugar que seja seu, "não nos causa surpresa que o assassinato do pai possa aparecer como não violento" (FÉDIDA, 1996, p. 51). No caso do estrangeiro refugiado, o parricídio assume forma de esquecimento/ arquivamento, de recomeço, permanecendo apenas enquanto linguagem, narrativa, que promete se dar em outra língua, na língua do outro, pois, segundo Fédida (1996, p. 46), "o ato parricida seria gerador de seu enunciado mítico, no sentido em que destinaria à fala do mito dar-se a origem de sua emergência e esta fala tornaria o acontecimento anacrônico justamente ao reconhecer-lhe o poder de engendrar a linguagem".

Na mitologia grega, evocada por Freud (1980), vemos em Édipo um caminho para a compreensão da condição do refugiado e da condição humana. Édipo era parricida e, por isso, tornou-se errante, exilado, em busca de abrigo. Ao reler o texto freudiano, Fédida (1996, p. 45) argumenta que "o mito de um assassinato efetua uma separação entre uma imagem de violência que excita a violência e a inscrição do ato que faz apelo à linguagem para que receba sua marca". Trata-se, portanto, com o exílio, de uma ressimbolização, de um colocar em linguagem a violência, mantê-la na memória ou na a-memória, mas também de manter-se às voltas com toda tirania, vigilante quanto às novas formas possíveis de totalitarismo, conforme Natahi (2007), pois

Aquele que se viu às voltas com a questão do estrangeiro experimenta a violência de ter desertado a relação com a filiação e com a ancestralidade, voltando a questionar as ficções simbólicas que o ligam à comunidade. Aqui, a idéia é a de uma travessia do parricídio não exatamente como passagem ao ato, e sim como pura e incessante interrogação que faz circular as articulações simbólicas entre o ser e o mundo. O estrangeiro visa desarrumar toda metáfora paterna ${ }^{2}$ (NATAHI, 2007, p. 162).

É neste sentido que, como colocávamos inicialmente, assumir uma posição de questionamento incessante, na Universidade ou não, aproxima-nos do errante, do migrante, do refugiado, posto que implica não aceitarmos como estáveis e imutáveis as relações que, simbólica e não naturalmente, articulam-se nesse espaço. Todavia, como compreender as transformações demandadas pela migração e, ainda, como possibilitá-las, de modo a não retornarmos sempre aos mesmos formatos, aos mesmos lugares? Esta é, em nosso entendimento, uma questão que envolve a hospitalidade, pois, se o refugiado, como o próprio nome assegura, não mais busca

2. Grifos nossos. 
refúgio, mas supostamente já o encontrou, em que e em quem se refugia? Quem o acolhe e de que forma?

\section{DA HOS(TI)PITALIDADE INSTITUCIONAL}

Nos termos de Derrida (2000), acolher o estrangeiro em situação vulnerável não advém de um amor aos outros, não se trata de uma questão filantrópica ou sentimental, mas de uma obrigação, de uma dívida, reguladas por lei. Além disso, para o autor, o termo hospitalidade engloba diversas questões: históricas, éticas, jurídicas, políticas e econômicas. São essas as problemáticas que circunscrevem a situação de refúgio contemporaneamente, atravessadas, neste estudo, por uma questão de saber/conhecimento, quando aos refugiados é permitido se inserir na Universidade, terreno do Logos, da razão. Ocupar esse espaço, contudo, não reduz o problema ao saber, pois exacerba as questões anteriores. Ingressar no ensino superior ou poder continuar seus estudos em outro país (re)insere o refugiado na dinâmica das relações de trabalho, na busca de ascensão social e cultural e na luta por visibilidade, configurando-se, por fim, como um embate ético por direitos.

Articular tais questões com a (e na) Universidade não objetiva, assim, encerrá-las em um espaço definido, não visa a enclausurá-las, mas a "encontrar o melhor acesso a um novo espaço público, transformado por novas técnicas de comunicação, de informação, de arquivamento e de produção de saber" (DERRIDA, 2003 , p. 16). Quando se trata do acesso a um ensino superior de qualidade como um gesto de acolhida, estaria em pauta uma questão de direito, não de moral nem de política. Direito, mais precisamente, de pertencimento a uma comunidade, de "estar com" o outro, de ter seus saberes por ele reconhecidos e de também produzir conhecimento. Essa acolhida aponta, no entanto, para o cerne da questão da hospitalidade. A palavra, desde a origem latina, é contraditória em sua constituição, uma vez que é parasitada, afirma Derrida (2000, p. 3), por seu oposto, hostilidade, já que ambas possuem o mesmo radical. Desse modo, o refugiado, que não foi convidado, mas precisou vir mesmo sem o ser, não conta senão com este gesto de hospitalidade: "é um estranho tratado como amigo ou aliado", mas ainda assim um estranho, o que pode justificar a fácil passagem da hospitalidade à hostilidade, noticiada, por exemplo, quando se trata de agressões vivenciadas pelos migrantes, em geral, no país.

Além disso, há outro ponto perverso na lógica da acolhida. Ainda nos termos

de Derrida (2000, p. 4), "a hospitalidade é, certamente, um direito, uma dívida, uma obrigação, mas com a condição de que [...] aquele que recebe, hospeda ou dá asilo 
permaneça o patrão, o chefe da casa" ${ }^{\prime \prime}$. Assim, aquele que ocupa o lugar de senhor, de dono, de mestre é quem dita as regras, e suas condições é que devem ser seguidas por aquele que chega. Toda lei da hospitalidade, inclusive de acolhida no ensino superior, implica dar um lugar, mas, como já sabemos, dar lugar significa delimitar esse lugar, impor-lhe condições que devem ser aceitas por quem quiser ocupá-lo.

Ora, se estabelecemos condições, se legislamos sobre a hospitalidade, não acolhemos o outro como tal, como alteridade (alter, o outro), em suas diferenças. Eis o paradoxo derridiano: só se poderia exercer hospitalidade se ela fosse incondicional, ou seja, sem nenhuma condição, exatamente por se tratar de um direito. Mas seria isso possível? Estaríamos prontos a aceitar o outro em sua estranheza radical? Responder a essa questão envolve uma dimensão ética, na medida mesma em que a ética se relaciona à responsabilidade, à resposta ao outro, um outro que, no caso deste estudo, é também de ordem institucional.

Quando tomamos como foco as instituições, estamos diante de lugares cujos discursos são vistos como legítimos e autorizados. Todavia, contemporaneamente, as instituições assumem múltiplas faces e seu papel varia de acordo com os sujeitos e com as condições de produção em que atuam. Elas deixam de lembrar apenas espaços físicos e, devido ao advento das relações sociais em rede, tomam um lugar na virtualidade, ou seja, na dimensão de potencialidade que essa noção comporta.

Sendo assim, os discursos institucionais passam a ser não apenas aqueles enunciados de uma posição juridicamente legitimada, da qual "os locutores, instados a responder por exigências complexas e até contraditórias, obedecem a uma injunção mais geral: organizar a polifonia, reduzir a dissonância, produzir a coerência" ${ }^{\prime 4}$ (KRIEG-PLANQUE e OGER, 2010, p. 93), mas também todo conjunto de regras que define o que pode e deve ser dito e feito nas esferas pública e privada, cerceando, assim, o enunciador. Para Deleuze (1992, p. 216), "estamos entrando nas sociedades de controle, que funcionam não mais por confinamento, mas por controle contínuo e comunicação instantânea" e as instituições têm aderido a esse modo de configuração.

Contudo, apesar da nova roupagem, os efeitos de sentido e o funcionamento do discurso institucional permanecem semelhantes. Marcas da textualização desse discurso sempre foram o caráter imperativo e prescritivo, embora camuflado, de sua

3. Tradução nossa para: "hospitality is certainly, necessarily, a right, a duty, an obligation [...] but on the condition that the [...] the one who receives, lodges or gives asylum remains the patron, the master of the household" (grifos do autor).

4. Tradução nossa para: "les locuteurs, sommés de répondre à des exigences complexes voire contradictoires, obéissent à une injonction plus générale : organiser la polyphonie, réduire la dissonance, produire la cohérence 
linguagem. Porém, acrescidas a estas, e características das interações contemporâneas, estão as tendências à "despolitização" dos dizeres, ao "apagamento dos conflitos" (KRIEG-PLANQUE e OGER, 2010), ao politicamente correto, à amenização ou à "docilização" dos discursos (SARGENTINI, 2017), tanto no âmbito de um mesmo texto/dizer quanto na relação de troca entre interlocutores.

Esse imperativo, que dissimula a heterogeneidade intrínseca à linguagem e as contradições características dos discursos, tem encontrado legitimação na mídia, no cenário político, como apontam os estudos de Sargentini (2017), mas também nos âmbitos jurídico e acadêmico. Tal tentativa de apagamento dos conflitos e das contradições, no entanto, não anula a opacidade nem a porosidade do discurso, de modo que se pode sempre realizar uma torção nesses dizeres, com vistas a mostrar que, "de certa maneira, todo enunciado prescritivo remete profunda - ou implicitamente - às transgressões que suscita"5 (OGER e OLLIVIER-YANIV, 2003). É para os dizeres institucionais, aparentemente dessubjetivados, que regulamentam a hospitalidade, mas potencializam a hostilidade, por serem carregados de poder, que direcionamos nosso olhar.

A análise empreendida a seguir dedica-se à abordagem de documentos, por meio dos quais se buscou compreender o funcionamento do discurso institucional como estabilizador de sentidos e silenciador de possíveis conflitos. Em sentido amplo, segundo Oger e Ollivier-Yaniv (2003),

O discurso institucional (institucionalizado e institucionalizante) pode compreender o conjunto de discursos que se pode considerar, em graus diversos, como discursos "autorizados" em dado meio, sem referência necessária ao Estado (produções de sindicatos, de partidos políticos, associações profissionais, programas e regimentos de escolas privadas...) (OGER e OLLIVIER-YANIV, 2003, p. 128) ${ }^{6}$.

Porém, quando analisamos a documentação que regulamenta o ingresso de pessoas em situação de refúgio no ensino superior brasileiro, mais precisamente em universidades públicas, tomamos o discurso institucional, em sentido estrito, como produto oficial de uma posição, geralmente coletiva, juridicamente inscrita e representada pelo que se compreende por Estado. Nesse sentido, o discurso institucional está relacionado a políticas públicas, as quais se inserem em um conjunto

5. Tradução nossa para : « d'une certaine manière, tout énoncé prescriptif renvoie en creux - ou implicitement - aux transgressions qu'il suscite ».

6. Tradução nossa para: "le discours institutionnel (institutionnalisé et institutionnalisant) peut comprendre l'ensemble des discours que l'on peut considérer à des degrés divers comme des discours « autorisés » dans un milieu donné, sans référence nécessaire à l'Etat (productions des syndicats, des états-majors des partis politiques, chartes des associations professionnelles, programmes et règlements d'écoles privées...) » 
de outras práticas previstas em leis referentes à acolhida de refugiados; políticas estas que podem ser lidas como formas de governamentalidade (FOUCAULT, 2010), modos de inserir e agenciar corpos em espaços delimitados. Em outros termos, a exemplo dos demais países, o Brasil tem vivenciado a necessidade de se posicionar enquanto Estado frente aos problemas migratórios atuais. Destacamos, contudo, que, se há necessidade de se legislar sobre a hospitalidade, de modo geral, mas, principalmente no âmbito da produção de conhecimentos, é porque estes, vindos de outros lugares, não são reconhecidos como tais, não são validados pelas instituições, talvez, por serem marcados por outras línguas-culturas, as quais, por sua vez, apesar de todo o imperativo pela "internacionalização das universidades" que temos vivenciado, acabam por ser menosprezadas, assim como seus falantes.

\section{SABER A LÍNGUA, CONHECER A LEI}

Partimos do pressuposto de que vivenciamos um período de maior acessibilidade ao ensino superior, a qual tem sido fomentada por programas governamentais e pelo envolvimento das universidades em ações afirmativas, tais como as políticas de cotas para estudantes indígenas, afrodescendentes, Quilombolas e pessoas de baixa renda, além do ingresso via Sistema de Seleção Unificada (SiSU), possibilitado pela realização e ampliação do Exame Nacional de Ensino Médio (ENEM). Apesar desse pressuposto, segundo o qual há maior acessibilidade e inclusão no ensino superior, principalmente nas universidades públicas, talvez estas ainda não sejam inclusivas quanto aos saberes múltiplos com os quais têm se defrontado, principalmente quando estes divergem do conhecimento escolar, acadêmica ou cientificamente reconhecido.

$\mathrm{O}$ momento histórico em que se inscreve este estudo compreende as primeiras décadas do século XXI, nas quais se desencadearam as chamadas crises migratórias, resultantes de desastres ambientais, de perseguições políticas, de conflitos armados, dentre outras razões. Segundo o ACNUR (Alto Comissariado das Nações Unidas para Refugiados), o Brasil abriga hoje mais de 10 mil refugiados ${ }^{7}$ reconhecidos, população majoritariamente composta por adultos jovens (de 18 a 40 anos). Considerando esse cenário, nossas universidades têm se proposto a oferecer-lhes acesso "facilitado" à formação de nível superior, com base na Lei $\mathrm{n}^{\mathrm{O}}$. 9.474/1997. Contudo, o número de refugiados ingressantes via processos seletivos

7. Disponível em: http://www.acnur.org/portugues/wp-content/uploads/2018/04/refugio-em-numeros_1104.pdf 
diferenciados é pouco significativo. A título de exemplo, de acordo com uma das instituições pioneiras nessa política de acessibilidade, seu contingente maior de estudantes refugiados, registrado até 2016, foi de sete pessoas. Contraditoriamente, como apontamos em estudo precedente,

Mesmo que o país disponha de universidades públicas com programas específicos de ingresso direcionados aos refugiados, sua formação educacional superior nem sempre é possível, fazendo com que se privem não só do acesso a um ensino público de qualidade e a uma formação profissional que lhes permita reconstruir suas vidas, mas também de visibilidade e representatividade social e cultural (DA ROSA, 2018, p. 163).

Esse paradoxo nos levou a indagar sobre os possíveis fatores que interferem na eficácia dessa política de hospitalidade e, mais pontualmente, sobre o papel que a língua portuguesa, como língua de acolhida, exerce nesse processo. $\mathrm{O}$ corpus deste estudo foi, então, composto por editais, portarias e resoluções, formulados e publicados, on-line, por sete IES ${ }^{8}$ públicas brasileiras. Pode-se inferir, inicialmente, que os refugiados não procuram pelo ingresso nas universidades públicas devido à falta de informação, visto que os programas não são divulgados em detalhes nem mesmo nas páginas oficiais das IES que os propõem. Porém, é possível pressupor também que, além da divulgação lacunar, a própria regulamentação, como o texto dos editais, quando acessível, mostra-se linguisticamente uma barreira a esse acesso, conforme se pode observar em alguns dos recortes analisados, o que aponta para o caráter cerceador, regulador e restritivo do discurso institucional.

Frente ao corpus de análise, então, vemos que uma das marcas dessa hospitalidade condicionada é o (re)conhecimento da língua portuguesa, língua do outro, que pode ser observado nos excertos seguintes:

(1) 5. A seleção simplificada consistirá da realização de uma Prova de Redação, em Lingua Portuguesa, elaborada, aplicada e corrigida por comissão designada pela Pró-Reitoria de Graduação (Edital IES1, 2016) ${ }^{9}$.

Em (1), o ingresso do estudante refugiado na universidade parece não ser tão facilitado como manda a lei nem tão simplificado como afirma o edital, pois é preciso que ele saiba, de antemão, no mínimo, em que consiste uma Prova de Redação,

8. Universidade Federal de São Carlos (UFSCar), Universidade Federal de Minas Gerais (UFMG), Universidade Federal de Juiz de Fora (UFJF), Universidade de Brasília (UnB), Universidade Federal do Rio Grande do Sul (UFRGS), Universidade Federal do Paraná (UFPR) e Universidade Federal de Santa Maria (UFSM).

9. Os grifos nos excertos analisados são nossos. Não identificamos as instituições por não ser objetivo deste trabalho individualizá-las, mas tomar como ponto de partida seus textos documentais, a fim de problematizar o discurso institucional em sua constituição e funcionamento. 
o que não é especificado no documento. Ora, como sabemos, o que se chama de "Redação" não se caracteriza como um gênero textual/discursivo específico, como uma carta, um artigo de opinião, um relato de experiência. Sendo assim, longe de considerar a situação desfavorável do refugiado, visando, em primeira instância, a inseri-lo, a exigência da prova de redação, gênero impreciso, e em língua portuguesa (entende-se, língua oficial, padrão) pode, pelo contrário, barrar o ingresso no ensino superior, pois, independentemente de outros saberes que o estudante-refugiado possa possuir, mesmo saberes academicamente reconhecidos, como cursos de graduação em andamento em seus próprios países, é uma prévia inserção linguística, que se exige. Essa barra instaurada pela língua-cultura de quem hospeda não representa apenas a dificuldade de acesso nas IES, mas o cerceamento, a castração imposta pelo sistema simbólico desse outro país, por suas leis, pois, para Derrida e Dufourmantelle (2003),

O estrangeiro é, antes de tudo, estranho à língua do direito na qual está formulado o dever de hospitalidade, o direito ao asilo, seus limites, suas normas, sua polícia, etc. Ele deve pedir a hospitalidade em uma língua que, por definição, não é a sua, aquela imposta pelo dono da casa o hospedeiro, o rei, o senhor, o poder, a nação, o Estado, o pai, etc. [...] A questão da hospitalidade começa aqui: devemos pedir ao estrangeiro que nos compreenda, que fale nossa língua, em todos os sentidos do termo, em todas as extensões possíveis, antes e a fim de poder acolhê-lo entre nós? (DERRIDA; DUFOURMANTELLE, 2003, p. 15).

Essas palavras nos levam a depreender que, já nesse primeiro excerto, o que se demanda é uma (im)possível inserção linguística do estudante refugiado que, como estrangeiro, não necessariamente conhece a língua portuguesa ou não a conhece em sua forma escrita ou, ainda, não a conhece na modalidade escrita formal, solicitada corriqueiramente nas redações escolares. Além disso, o funcionamento do discurso institucional se faz ver no tempo do verbo "consistir", conjugado no futuro do presente do modo indicativo, que, embora não indique ordem, pois não se apresenta claramente como imperativo, tampouco sugere abertura à incerteza, à reformulação ou à possibilidade de que o processo se dê de outra forma.

Um funcionamento semelhante desse discurso é apresentado em (2), a seguir:

(2) Art. $7^{\circ}-\mathrm{O}$ aluno de graduação ingressante nessa condição iniciará as atividades em seu curso acadêmico após a apresentação, junto ao órgão competente em efetuar o registro discente, do certificado Celpe-Bras - Certificado de proficiência em língua portuguesa para estrangeiros [...]

$\$ 2^{\circ}-\mathrm{O}$ aluno ingressante com base na presente Decisão deverá apresentar em até 365 dias, contados de seu ingresso, o certificado CelpeBras, sob pena de extinção de seu vínculo com a [sigla da IES] (Edital IES2, 2015). 
Juridicamente legitimado e constitutivo do discurso institucional, o excerto em questão é engendrado por (e engendra) mecanismos de controle e cerceamento, os quais influenciam na formação de um saber sobre o estrangeiro-refugiado: a exigência reiterada de um comprovante que certifique sua proficiência linguística, "sob pena de extinção de seu vínculo", pressupõe, ao mesmo tempo, que o estrangeiro não a possui. Em primeira ordem, o refugiado é destituído não só de sua própria língua (que passa a não ter valor algum), mas também dos saberes/experiências nela vivenciados. E "vocês sabem que os exilados, os deportados, os expulsos, os desenraizados, os nômades têm em comum dois suspiros, duas nostalgias, seus mortos e sua língua..." (DERRIDA; DUFOURMANTELLE, 2003, p. 92). Em um momento de "internacionalização" das universidades brasileiras, em que muitos dos congressos científicos no próprio país se abrem a línguas estrangeiras (mas não quaisquer línguas), a exigência de inserção do refugiado na língua portuguesa por meio de um exame que afere sua proficiência possui um efeito limitador.

Marcas que apontam para o caráter imperativo, prescritivo e coercitivo do discurso institucional ("deverá... sob pena de") - embora, algumas vezes, camuflado, docilizado (como no emprego do futuro do presente em "iniciará... após") -, permitem compreender que a materialidade analisada funciona também como instrumento de poder. Retomando os termos de Derrida e Dufourmantelle, citados anteriormente, as leis da hospitalidade instituídas demandam "ao estrangeiro que nos compreenda, que fale nossa língua, em todos os sentidos do termo, em todas as extensões possíveis"; que nos compreenda não apenas em termos linguísticos e culturais, mas também legais, pois, como assegura um dos editais em análise, no excerto (3):

(3) ao protocolar o pedido de acesso a curso de graduação [...], o interessado aceita, de forma irrestrita as condições contidas nesse Edital [...] não podendo alegar desconbecimento (Edital IES3, 2015).

Esse estrangeiro deve, ainda que não tenha condições para tanto, submeter-se à língua do hospedeiro, daquele que, ao/por dar refúgio, reafirma-se como senhor, autoridade em sua casa. Submeter-se à sua língua implica, igualmente, submeter-se às suas leis, "obedecer a todas as exigências especificadas na legislação" (Edital IES3, 2015), (re)conhecê-las, não podendo alegar desconhecer, em última instância, seu lugar de estrangeiro-refugiado, posto que "os alunos ingressantes por essa via terão os mesmos direitos e deveres dos demais alunos [...], ressalvadas as distinções relativas à situação de refúgio" (Art. 8 , Edital IES2, 2015, grifo nosso). Tais distinções, todavia, não são especificadas no texto institucional, o que diminui sua capacidade de 
funcionamento como texto de caráter também instrucional, sugerindo a evidência dos sentidos e o caráter inquestionável da lei.

No excerto (4), a seguir, a lei que define o Estatuto do Refugiado é claramente citada, sugerindo, por um lado, que o estudante refugiado não pode ousar desconhecê-la e, por outro, que sua validade sustenta, consequentemente, o documento em questão:

(4) Art. 2o Não será aceita candidatura para admissão na condição de refugiado o indivíduo que seja enquadrado em pelo menos umas das seguintes condições:

não se beneficie da condição de refugiado por atender ao art. $3^{\circ}$ da Lei ${ }^{\circ}{ }^{0}$ 9.474/1997;

concluiu o ensino médio no Brasil (Resolução do Conselho de Ensino, Pesquisa e Extensão, IES4, 2007).

O artigo $3^{\circ}$ da referida lei, com a qual dialoga a Resolução, trata de quatro aspectos que não permitem atribuir ao estrangeiro a condição de refugiado: 1) já ter proteção de outro organismo da $\mathrm{ONU}$ que não o $\mathrm{ACNUR}$, 2) já atender às condições de "nacional brasileiro", 3) ter cometido crimes de diversas ordens, de crime contra a humanidade a tráfico de drogas e 4) ser considerado culpado de atos contra os princípios da ONU. Tais elementos, uma vez que impedem a alguém ser considerado refugiado e, portanto, ser reconhecido e ingressar como refugiado onde quer que seja, não serão discutidos nesta análise. Contudo, ter concluído o ensino médio no Brasil merece destaque. O documento é de 2007, época em que o fluxo migratório para o país não era tão significativo quanto dez anos depois. De todo modo, ter cursado o ensino médio (ou tê-lo concluído) no país de acolhida possibilitaria ao estudante-refugiado, minimamente, inserir-se nas exigências de caráter linguístico que vimos apresentadas nos demais documentos até aqui analisados. Se, inicialmente, poderíamos pensar que o "ingresso facilitado" seria um direito concedido apenas àqueles já inseridos linguística e socialmente no país, o excerto (4) sugere que se trata, como bem pontua Derrida, "do direito acordado ao estrangeiro enquanto tal, ao estrangeiro que continua estrangeiro" (DERRIDA; DUFOURMANTELLE, 2003, p. 21); direito que não necessariamente lhe garante a experiência de ter (outro) lugar.

Nesse sentido, ainda a partir da reflexão do autor, é possível pensar que o discurso institucional (e, por extensão, a própria lei) se apresenta passível de perversão, pois só acolhe o diferente se ele se mantiver em seu devido lugar, partindo do pressuposto de que as identidades são essências cristalizadas, não transformáveis. Nas palavras de Coracini (2010), aos refugiados, assim como a qualquer migrante, 
seria oferecida a "hostipitalidade", neologismo derrideano, que une, sem unir, hospitalidade e hostilidade: ao mesmo tempo que se acolhe, se hostiliza o diferente, o estranho, o estrangeiro que traz consigo diferenças perturbadoras da ordem dos discursos vigentes na sociedade que acolhe sem acolher, que protege sem proteger (CORACINI, 2010, p. 98).

Por fim, podemos considerar que a abertura de editais com vistas ao ingresso "facilitado", por meio de "seleções simplificadas", de estudantes em situação de refúgio em nossas universidades sugere um gesto de hospitalidade ao estrangeiro, mas seria ela incondicional?

A partir da leitura dos documentos institucionais que regulamentam o ingresso dos refugiados nas universidades públicas brasileiras, observamos que o aprendizado formal da língua portuguesa, nos moldes do ensino escolarizado, é visto como uma das condições para a (re)inserção sociocultural do estrangeiro no país, ou seja, para sua hospitalidade, que não é, portanto, sem condição. Para que haja essa acolhida no/pelo lugar tido como o "templo do saber", do Logos - palavra, razão, mas também busca constante pela verdade - o aprendizado da língua nacional tem sido visto como determinante, uma vez que o ingresso do estudante resulta de sua aprovação em exames que demandam "proficiência linguística". Porém, ter sido escolarizado no país e, consequentemente, ter passado por esse aprendizado formal também se apresenta como um fator limitador. Assim, mais do que a proficiência linguística, deve o estrangeiro ser juridicamente proficiente, a tal ponto que o ingresso facilitado na Universidade, que implica não só a inserção em uma comunidade linguística, mas também científica, soa esvaziado, quando não contraditório.

No discurso institucional, contudo, as contradições são estabilizadas, os dizeres são docilizados e os possíveis conflitos são silenciados pelo amparo na Lei, em que se busca respaldo, seja pela referência direta, como no excerto (4), seja pela referência indireta, no excerto (1), em que "seleção simplificada" relembra que "o reconhecimento de certificados e diplomas [...] e o ingresso em instituições acadêmicas de todos os níveis deverão ser facilitados". Esse discurso, portanto, fala a língua do direito em que se assegura o dever de hospitalidade, ainda que esta seja parasitada por seu oposto.

\section{CONSIDERAÇÕES FINAIS}

O objetivo deste estudo foi o de problematizar não apenas a formulação do discurso sobre os refugiados nos documentos que legislam acerca de seu ingresso na universidade pública brasileira, mas também o funcionamento do discurso institucional nas políticas de acolhida e hospitalidade ao estrangeiro. Tomando 
como ponto de partida as condições de produção atuais, marcadas pela emergência desses discursos institucionais, exploramos o paradoxo daí resultante, qual seja, a desproporcionalidade entre o aumento de universidades com programas que facilitariam o ingresso de refugiados e o reduzido número de estudantes que, de fato, ingressam nesses novos lugares.

É verdade que o acesso à informação, ainda que na chamada era digital, consiste em um grande entrave para que todos os editais, portarias e resoluções circulem e atinjam públicos variados. É também verdade que a Universidade ainda é representada como um ideal distante e inalcançável, podendo não ser considerada um lugar possível pelos próprios estudantes refugiados, dado que as políticas de acessibilidade são relativamente recentes. Contudo, ao refletir sobre a problemática do estrangeiro, Natahi (2007, p. 165) salienta que uma comunidade pode acolher, mas pode "do mesmo modo, tornar-se o túmulo em que se abole toda possibilidade de passar para uma outra borda, um outro lugar, e produzir novas sublimações"; comunidade que pode, também, designar lugares e não-lugares para aqueles que considera seus membros e seus intrusos.

Desse modo, enquanto docentes, principalmente na universidade pública, é importante que nos questionemos sobre a suposta abertura da instituição à tão sonhada internacionalização. Não seria este o momento de a internacionalizarmos, de fato, possibilitando que estudantes em formação nos países atingidos por diferentes formas de violência possam aqui produzir tanto conhecimento quanto novas narrativas sobre si mesmos? Como professores de línguas, também é tempo para analisarmos o papel que as línguas exercem na violação ou no respeito aos direitos humanos, de modo a pensarmos em seu ensino e na avaliação de sua proficiência para além do caráter meramente "linguístico", ou seja, estrutural, formalizado, escolarizado, institucionalizado, dialogando e contribuindo com o principal desafio vislumbrado pelo Relatório Mundial da UNESCO (2009, p. 4) neste século: "acompanhar a mudança cultural de modo a ajudar os indivíduos e os grupos a gerir mais eficazmente a diversidade".

Por fim, como seres políticos, urge que nos perguntemos sobre nosso papel no discurso institucional, na manutenção ou no questionamento dos espaços estáveis e da Universidade como lugar que ainda enclausura (e se enclausura para) o diferente. Trata-se de tomarmos uma posição, de assumirmos o lugar de problematização constante, aquele assumido por todos os que se desenraizam, deslocam-se, ainda que não fisicamente, tornando-se estrangeiros, não familiarizados com o familiar, com o 
natural. Essa é uma condição que devemos assumir, sem refúgio, uma condição que implica uma forma de parricídio como "pura e incessante interrogação", sem a qual se torna impossível qualquer identificação com o outro que nos questiona, que nos desestabiliza. Afinal, a lei assegura o dever de hospitalidade, mas não o de identificação ou o de reconhecimento da alteridade. Identificar-se incondicionalmente com um outro parricida - patricida - talvez nos seja hoje impossível e, por isso mesmo, nunca foi tão necessário.

\section{REFERÊNCIAS}

BRASIL. (1997). Lei n. 9474, de 22 de jul. de 1997. Define mecanismos para a implementação do Estatuto dos Refugiados de 1951 e determina outras providências. Brasília, DF, jul. 1997. Disponível em: http://www.planalto.gov.br/ccivil_03/leis/L9474.htm. Acesso em: 29 jul. 2016.

CORACINI, M. J. (2010). Transdisciplinaridade e análise de discurso: migrantes em situação de rua. Cadernos de Linguagem e Sociedade, 11 (1), pp. 91-112, 2010. Disponível em: http://periodicos.unb.br/index.php/les/article/view/1181/844. Acesso em: 07 jun. 2015.

DA ROSA, M. (2018). O funcionamento argumentativo em torno da designação "refugiados" no discurso universitário brasileiro. EID\&A - Revista Eletrônica de Estudos Integrados em Discurso e Argumentação. n. 15, jan-jun 2018, pp. 162-174. Disponível em: http://periodicos.uesc.br/index.php/eidea/article/view/1961/1536. Acesso em: 18 set. 2018.

DELEUZE, G. (1990). Conversações. Trad. Peter Pál Pelbart. São Paulo: Editora 34, 1992.

DERRIDA, J.; DUFOURMANTELLE, A. (1997). Anne Dufourmantelle convida Jacques Derrida a falar Da Hospitalidade. Trad. Antonio Romane. São Paulo: Escuta, 2003.

DERRIDA, J. (2001). A universidade sem condição. Trad. Evando Nascimento. São Paulo: Estação Liberdade, 2003.

DERRIDA, J. (2000). Hostipitality. Angelaki: Journal of the theoretical humanities. v. 5, n. 3, dez. 2000, pp. 3-18.

FÉDIDA, P. (1995). O sítio do estrangeiro. Trad. Eliana Leite, Martha Gambini e Monica Seincman. São Paulo: Escuta, 1996. 
FOUCAULT, M. (1979). Microfísica do Poder. Organização e tradução de Roberto Machado. Rio de Janeiro: Edições Graal, 2010.

FREUD, S. (1913). Totem e tabu. In: FREUD, S. Edição standard brasileira das obras psicológicas completas. Trad. J. Salomão. Rio de Janeiro: Imago, 1980, pp. 20-191.

FREUD, S. (1924). A dissolução do complexo de Édipo. In: FREUD, S. Edição standard brasileira das obras psicológicas completas. Trad. J. Salomão. Rio de Janeiro: Imago, 1980, pp. 215-226.

GLISSANT, E. (1995). Introdução a uma poética da diversidade. Trad. Enilce Albergaria Rocha. Juiz de Fora: EdUFJF, 2005.

KRIEG-PLANQUE, A.; OGER, C. (2010). Discours institutionnels. Perspectives pour les sciences de la communication. Mots. Les langages du politique n. 94, nov. 2010, pp. 91-96.

KRISTEVA, J. (1988). Estrangeiros para nós mesmos. Trad. Maria Carlota Gomes. Rio de Janeiro: Rocco, 1994.

NATAHI, O. (2007). Dinâmica do aberto e problemática do estrangeiro. Ágora. Rio de Janeiro. v. X n. 2 jul-dez 2007, pp. 159-170. Disponível em: http://www.scielo.br/ scielo.php? script $=$ sci arttext\&pid $=S 1516-14982007000200001$. Acesso em: 30 ago. 2017.

OGER, C.; OLLIVIER-YANIV, C. (2003) Analyse du discours institutionnel et sociologie compréhensive : vers une anthropologie des discours institutionnels. Mots: les langages du politique. Mondialisation(S), $\mathrm{n}^{\circ}$ 71, mar 2003, pp. 125-145.

ROBIN, R. (2003). Le denil de l'origine. Paris: Éditions Kimé, 2003.

SARGENTINI, V. M. (2017). Mutações do discurso político: segmentação, docilização e estetização. In: SARGENTINI, V. M. (Org.). Mutações do discurso político no Brasil: espetáculo, poder e tecnologias de comunicação. Campinas: Mercado de Letras, 2017, pp. 85106.

SILVA, M. B.; CREMASCO, M. V. (2015). Migração e refúgio, contribuições da Psicologia. Secretaria da Justiça, Trabalbo e Direitos Humanos; Departamento de Direitos Humanos e Cidadania. (texto não paginado). Disponível em: http://www.dedihc.pr.gov.br/modules/ conteudo/conteudo.php? conteudo=130. Acesso em 31 ago. 2017. 
UNESCO. (2009). Relatório Mundial da UNESCO: Investir na diversidade cultural e no diálogo intercultural. 2009. Disponível em: http://unesdoc. unesco.org/images/0018/001847/184755por.pdf. Acesso em: 01 mai. 2015.

Recebido: 10/02/2018

Aceito: 19/09/2018 